\title{
O Sujeito da Neurociência: da Naturalização do Homem ao Re-encantamento da Natureza
}

\author{
JANE A. RUSSO \\ EDNAL. T. PONCIANO ${ }^{2}$
}

\section{RESUMO}

O objetivo deste trabalho é circunscrever a concepção de sujeito que emerge das teorias neurocientíficas sobre a mente. Para tanto, abordamos três autores-chave do campo da neurociência: Francisco Varela, Humberto Maturana e Gerald Edelman. A partir da análise de seus trabalhos, concluímos que uma determinada concepção de sujeito, calcada numa visão inteiramente materialista da mente, se apresenta como substituto vantajoso de uma concepção que poderíamos chamar de "psicológica", calcada principalmente, mas não exclusivamente, na psicanálise. Procuramos demonstrar a hipótese de que o atual sucesso da visão "neurocientífica" do ser humano, se de fato aponta para algum grau de ruptura com o chamado "paradigma moderno", também pode ser interpretado como a radicalização de determinadas características e contradições presentes na própria constituição desse paradigma e, por conseqüência, da pessoa moderna.

Palavras-chave: Neurociência; pessoa moderna; mente. 


\begin{abstract}
Nous en sommes au début de la révolution des neurosciences. Lorsqu'elle sera achevée, nous saurons comment fonctionne l'esprit, nous comprendrons ce qui régit notre nature, et aussi comment nous faisons pour connaître le monde. En fait, ce qui se passe actuellement en neurosciences peut être consideré comme le prélude à la plus grande des révolutions scientifiques, une révolution aux répercussions sociales inévitables et fondamentales. (Edelman, 2000a, Prefácio).

O corpo subiu-lhe à cabeça. (Frase atribuida a Dorothy Parker, citada em Damásio, 1998, p. 254).
\end{abstract}

Vivemos atualmente a hegemonia do paradigma biológico no campo científico. O modelo da física enquanto ciência paradigmática estaria cedendo lugar ao modelo do organismo calcado na biologia (Bezerra Jr., 2000). O que poderíamos chamar de "ufanismo" biológico se expressa, por um lado, em conquistas cada vez mais ousadas no campo da biotecnologia. Por outro, num plano que poderíamos chamar de ideológico, assistimos ao ressurgimento, a partir dos anos 70/80 do século passado, de trabalhos científicos calcados num forte determinismo biológico, implicando a interpretação biologizante de uma vasta gama de comportamentos e fenômenos, tais como a diferença de gênero, a homossexualidade, as diferenças de performance escolar, diferenças raciais, além, evidentemente, das chamadas "doenças mentais", cujo fundamento psicológico é descartado em favor de prováveis disfunções do sistema nervoso.

Em meio a essa "voga biológica", a chamada neurociência vem propor uma leitura radicalmente naturalizante e materialista da mente humana, pretendendo superar a tradicional visão dualista que separa o homem em corpo e mente.

Buscaremos, neste trabalho, circunscrever a concepção de sujeito que emerge das teorias neurocientíficas sobre a mente, procurando determinar o que o aproxima ou o afasta do chamado sujeito moderno.

\title{
Algumas Questões Preliminares
}

Iniciaremos com o relato de um desenho animado, episódio de uma série bastante popular nos dias que correm (As Meninas Superpoderosas), que uma das autoras assistiu pela televisão. 
No episódio em questão, um dos personagens - um cientista - conseguira inventar um raio que, transmitido pelo ar através de uma antena, trocava os corpos das pessoas. Ou seja, uma das meninas superpoderosas acordara de manhã no corpo do prefeito, este por sua vez acordara dentro do corpo de sua secretária. O próprio cientista encontrava-se dentro de um corpo que não era o seu. O sinal que indicava a "verdadeira pessoa" dentro do corpo errado era a voz dos personagens. Algumas premissas sobre "corpo" e "pessoa" - premissas que fundamentam o senso comum de modo que qualquer criança entenda - estão aí colocadas. Em primeiro lugar, é evidente, a premissa de que "pessoa" é uma coisa e "corpo" é outra. Isto é, há algo, uma substância, que define a "pessoidade" (ou a identidade) de alguém e que, não apenas não se reduz à sua aparência física imediata, como tem uma existência própria, independentemente dessa aparência, podendo, por isso, migrar de uma aparência (corpo) para outra.

Usamos o termo "aparência" de propósito, já que nos parece evidente a oposição entre a aparência (do corpo) versus uma essência "imaterial" (que curiosamente se materializa na voz, que, por sua vez, é também uma matéria invisível) que dele independe. Outra oposição subjacente é a que distingue entre dentro e fora. A pessoa, de fato, embora esteja dentro de um corpo, não é esse corpo. Enquanto uma essência, a pessoa é mais que o corpo, está para além dele, embora de alguma forma a ele se ligue. Isto é, o que define a identidade de um sujeito, o que define aquilo que ele de fato é, não é sua aparência física (seu corpo), mas algo que está dentro desse corpo.

O fenômeno de almas, ou mentes, que migram de um corpo para outro, já foi tema de inúmeros filmes e romances dos mais populares aos mais intelectualizados. É muito comum, em obras de ficção científica, extraterrestres que, para invadir a Terra, invadem corpos de terráqueos. A força dessa representação do ser humano - como ser provido de um corpo mais alguma outra coisa que não é da ordem do corporal - no Ocidente é inegável. Reconhecemos seus fundamentos na cultura judaico-cristã que sustenta nossa visão de mundo e se constituiu em torno da oposição hierárquica entre corpo e alma. Reconhecemo-la, ainda, no dualismo que marcou, como se sabe, todo o empreendimento científico ocidental, através da noção de uma "razão desprendida" e de um sujeito desencarnado que se debruça sobre um mundo natural objetificado.

Apesar da força ainda visível nos produtos da cultura de massa, como o desenho animado descrito, tal representação parece apresentar sinais de 
esgotamento ${ }^{3}$. Acreditamos ser possível apontar tal esgotamento num conjunto de fenômenos de ordens e níveis diversos, que determinados autores identificam como indicativos de uma "crise do paradigma moderno" ou do surgimento de uma pretensa "era pós-moderna".

Nosso objetivo é caracterizar o "sujeito da neurociência" como um dos signos desse esgotamento. Pretendemos demonstrar como uma determinada concepção de sujeito, surgida a partir dos avanços da neurociência, se apresenta como um substituto vantajoso de uma concepção que poderíamos chamar de "psicológica", calcada principalmente, mas não exclusivamente, na psicanálise. Ou seja, tratar-se-ia da substituição de uma visão dualista do humano, baseada na afirmação de um plano "psíquico" distinto do orgânico, por outra monista, que pretende fornecer uma leitura orgânica (ou naturalista) do que até então tem-se chamado psíquico (ou mental). Trabalharemos com a hipótese de que o atual sucesso da visão "neurocientífica" do ser humano, e conseqüente declínio da visão "psicológica", se de fato aponta para algum grau de ruptura com o chamado "paradigma moderno", também pode ser interpretado como a radicalização de determinadas características e contradições presentes na própria constituição desse paradigma e, por conseqüência, da pessoa moderna.

$\mathrm{O}$ fato de trabalharmos com concepções letradas de pessoa requer algumas observações. A primeira diz respeito ao fato de a ciência, a partir do esfacelamento de uma visão unitária e transcendente do mundo fornecida pela religião, apresentar-se como Weltanschauung, buscando fornecer interpretações que preencham os espaços deixados pela retração do poder explicativo da religião. Uma Weltanschauung que, sendo um produto da secularização e conseqüente desencantamento do mundo, guarda suas marcas: é fragmentada em diversos compartimentos que se comunicam em graus variáveis, está comprometida com a idéia de progresso e descobrimento, sendo suas teorias, portanto, passíveis de refutação e/ou superação. Por seu alto grau de especialização, depende de um corpo técnico altamente qualificado, que produz um conhecimento "esotérico" que não é acessível nem a outros especialistas, nem aos chamados leigos. No entanto, o conhecimento científico se difunde e acaba sendo incorporado, de forma modificada e/ou simplificada, pelo senso comum. A psicanálise é um bom exemplo dessa incorporação ${ }^{4}$.

Por outro lado, estamos lidando com um tipo de conhecimento que, estando na órbita da medicina e das ciências do comportamento, tem uma vocação "intervencionista" - isto é, um conhecimento que, para além de 
uma pura interpretação dos fatos, produz propostas de intervenção na vida das pessoas e das coletividades. Daí as análises de diversos autores que se referem a uma "medicalização", ou mesmo "psiquiatrização" da sociedade. Essa medicalização/psiquiatrização, como se sabe, implica não apenas intervenções diretas do poder público, mas uma penetração mais sutil e capilarizada no interior das famílias e na regulação das relações entre seus membros (Foucault, 1988; Donzelot, 1980; Castel, 1987; Costa, 1979). Neste sentido, poderíamos dizer que temos aí não apenas a produção de teorias sobre a pessoa, mas de verdadeiros modos de construção da pessoa.

Por isso acreditamos que examinar as novas teorias sobre a pessoa produzidas no âmbito da neurociência significa examinar uma nova forma de compreender/interpretar a pessoa que, ao mesmo tempo, indica novos modos de construção de si.

Uma segunda ressalva se faz necessária. Uma interpretação inteiramente fisicalista do ser humano vem sendo objetivo da psiquiatria desde seus primórdios. A interpretação psicológica da mente sempre conviveu com seu oposto, seja através da noção de hereditariedade ou dos esforços de localização cerebral dos distúrbios mentais. Entre meados do século XIX e início do XX, tais concepções foram mesmo hegemônicas no campo. Ainda assim, a distinção orgânico/psíquico permanecia como pano de fundo, o que se expressava na própria divisão do campo em duas especialidades - psiquiatria e neurologia.

Embora essa divisão permaneça, a moderna designação "neurociência" parece ser uma clara tentativa de ultrapassá-la. Além do mais, o surgimento desse novo ramo científico parece estar ancorado em um movimento cultural mais amplo que, do nosso ponto de vista, o distingue das leituras fisicalistas empreendidas no século XIX. Gostaríamos de explicitar melhor essa distinção.

Isso que estamos chamando de movimento cultural mais amplo pode ser descrito como uma forte reação anti-racionalista, que floresce na segunda metade do século XX, calcada na crítica contundente à idéia de que há uma base racional para os fenômenos humanos que permite compreendê-los de forma previsível, e ao uso de categorias universais como base do conhecimento. Sua influência nas ciências humanas e na filosofia foi marcante, expressando-se no abandono de ou crítica aos grandes esquemas explicativos e concomitante adoção de um individualismo metodológico - que, por sua vez, implicou a ênfase na historicidade dos fenômenos e na sua especificidade e/ou originalidade, a afirmação da multiplicidade/pluralidade de fatores 
explicativos, a crítica à rígida separação entre um sujeito do conhecimento e objeto a ser conhecido. Ao lado de sua face mais letrada, é possível reconhecê-lo nas diversas manifestações da cultura da juventude que, a partir de finais dos anos 60 do século passado, surgiram nos países centrais e seus satélites e que se convencionou reunir sob a rubrica "contracultura" 5 .

De fato parece um tanto difícil explicar a ancoragem de um novo ramo da ciência em um movimento claramente anti-racionalista e praticamente anticientificista. Esperamos esclarecer esse argumento no decorrer do trabalho. Por enquanto, consideramos importante apontar duas características do referido movimento que nos parecem relevantes para a construção de nosso argumento.

Em primeiro lugar, a crítica à "razão desprendida" e à separação sujeito/ objeto implica uma "reencarnação" do sujeito - isto é, este não poderá mais ser pensado como um sujeito do conhecimento desprendido de sua experiência "carnal" no mundo que pretende conhecer. Neste sentido, o antiracionalismo contracultural encerra uma crítica à concepção dualista físico/ mental a que nos referimos no início do trabalho. Em segundo lugar, esta reencarnação permite articular a valorização do individual, do específico, do idiossincrático, à afirmação de uma totalidade físico-moral em sentido amplo. Isto é, não apenas o ser humano pode/deve ser compreendido como uma totalidade físico-moral, mas o próprio ambiente em que ele vive não mais comporta esse tipo de separação.

Esse movimento cultural mais amplo, que poderia ser descrito como uma voga neo-romântica pelo seu aspecto anti-racionalista e antidualista, é paralelo a uma hegemonia das ciências biológicas no campo científico mais geral, à qual nos referimos em nossa introdução. $\mathrm{O}$ movimento contracultural e a voga biologizante parecem, à primeira vista, incompatíveis, dada a preocupação objetivante e cientificista desta. Procuraremos demonstrar que a neurociência, constituindo importante vertente dessa "virada biológica", se aproxima da ideologia subjacente ao movimento contracultural, ao afirmar um monismo naturalista, que praticamente extingue o mental (ou o psicológico) como realidade sui generis, construindo uma visão totalizante e "encorporada" do ser humano.

Uma vez feitas essas observações preliminares, é necessário esclarecer a via escolhida para abordar o tema do "sujeito da neurociência". A neurociência faz parte das chamadas "ciências cognitivas" - termo que por sua vez designa um conjunto de saberes congregados em torno do objetivo de explicar cientificamente (ou materialmente) o "espírito", a saber, a psico- 
logia cognitiva, a epistemologia (filosofia da mente), a lingüística, a inteligência artificial e a neurociência (Varela, s/d).

O campo da neurociência é, evidentemente, bastante vasto e heterogêneo. Não foi e não poderia ter sido nossa intenção abarcá-lo em toda sua multiplicidade. Escolhemos, em nossa abordagem, alguns autores-chave Francisco Varela, Humberto Maturana e Gerald Edelman - que nos pareceram representativos, não apenas de uma certa "vanguarda neurocientífica", mas de uma ambição explicativa mais abrangente e, sobretudo por serem autores que se dedicam à popularização das "descobertas" da teoria neurocientífica. Todos, em especial Varela e Maturana, estenderam sua influência para além do campo restrito da neurociência, empenhando-se em dialogar com outros campos de conhecimento e em propor uma espécie de nova filosofia acerca do espírito humano ${ }^{6}$.

Procuraremos, num primeiro momento, caracterizar o surgimento das ciências cognitivas e seu posterior desenvolvimento de modo a situar nossos autores. Em seguida, buscaremos expor suas teorias acerca do ser humano, de modo a construir o retrato, por assim dizer, do sujeito tal como é concebido pela neurociência. Numa última etapa, examinaremos esse retrato com o intuito de determinar afastamentos e aproximações com a concepção moderna de pessoa.

\section{A Neurociência no Campo das Ciências Cognitivas}

Em julho de 1990, o então presidente americano, George Bush, assinou uma proclamação declarando os anos 90 "a década do cérebro". A proclamação foi fruto de uma lei, proposta a partir de uma recomendação da comunidade neurocientífica, votada no ano anterior pelo Congresso norteamericano. $\mathrm{O}$ argumento que a sustentava baseava-se no impacto econômico negativo das diversas doenças e afecções do cérebro que estariam acometendo a população americana.

Subjacente aos argumentos econômicos, sustentados em estudos epidemiológicos e cálculos estatísticos, porém, estava (e ainda está) em jogo um novo modo de compreender e lidar com as perturbações ditas mentais. E, mais ainda, um novo modo de compreender e lidar com a própria mente. De fato, desde pelo menos meados dos anos 80, a mídia passou a alardear com insistência cada vez maior as conquistas científicas que justificariam a posterior proclamação de uma "década do cérebro".

Fizeram parte de tais conquistas determinados avanços tecnológicos - 
como as técnicas de neuroimagem estrutural e funcional através da ressonância magnética, da tomografia computadorizada, da tomografia por emissão de pósitrons (PET) e da tomografia por emissão de fótons (SPECT) que tornaram possível observar o cérebro em pleno funcionamento. As novas teorias sobre o funcionamento cerebral deixaram o campo restrito dos periódicos especializados e ganharam as manchetes das revistas de ampla circulação. Nestas se festejavam não apenas a descoberta dos mecanismos pelos quais a mente funciona, mas os usos de tal descoberta no tratamento de doenças mentais, na compreensão do desenvolvimento infantil, na prevenção de problemas da velhice, na promoção da inteligência e de outras faculdades mentais. Diversos best-sellers foram (e são) publicados em torno do tema, indo desde obras assemelhadas a livros de auto-ajuda, como $A$ inteligência emocional, de Daniel Goleman, até textos mais sérios de divulgação científica, como $O$ erro de Descartes - emoção, razão e o cérebro humano, de Antonio Damásio. Este, a começar pelo seu título, é um bom exemplo da abrangência pretendida por esse tipo de literatura de divulgação. O objetivo do autor, tal como descrito na "orelha" de sua edição brasileira, parece ultrapassar em muito a mera transposição de determinadas teorias para uma linguagem mais acessível ao grande público:

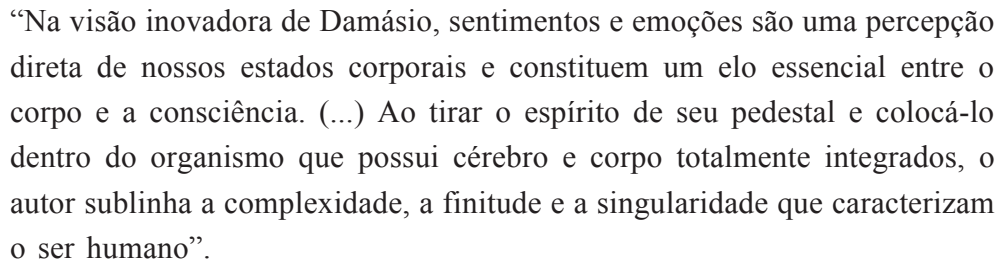

Toda essa agitação em torno do cérebro e seu funcionamento veio, na verdade, coroar o esforço de um conjunto de pensadores, filósofos e cientistas que, há algumas décadas, desenvolviam estudos reunidos sob a denominação de "ciências cognitivas".

Tudo começou, segundo reza a lenda, no final dos anos 40, a partir de uma série de conferências, organizadas pela Fundação Josiah Macy Jr., conhecidas como "Conferências Macy", que congregou biólogos, neurofisiologistas, matemáticos, antropólogos, psicanalistas, psicólogos e engenheiros, com o objetivo de criar uma ciência do espírito - isto é, uma ciência natural (não mentalista) da mente (Dupuy, 1994).

A ciência cognitiva surgida a partir das Conferências Macy foi batizada por Norbert Wiener como cibernética, no decorrer das conferências, entre 
1946 e 1953. O cerne dessa primeira formulação cognitivista era a analogia entre o funcionamento cerebral e o funcionamento de uma máquina, concretizada posteriormente no computador. Tratava-se de uma teoria representacional, a partir da qual considerava-se que a estrutura física do cérebro, tal como um hardware, seria alimentada por um conjunto de símbolos articulados através de uma gramática previamente estabelecida (uma espécie de software). A eficácia do modelo se basearia na correspondência entre as ações do organismo e as exigências externas, isto é, se os objetos externos estariam ou não sendo corretamente representados no cérebro.

Essa teoria sofre uma série de críticas, a partir dos anos 70, e uma segunda corrente cognitivista emerge, o chamado conexionismo, desta feita abandonando o modelo computacional em favor do organismo vivo. Baseada nos conceitos de auto-organização e emergência, a teoria conexionista trabalha com a noção de "redes neurais". O modelo input-output da vertente cibernética é abandonado: a informação (input) vinda do mundo externo deixa de ser fundamental para o desenvolvimento das capacidades cognitivas do cérebro. Ao contrário, a noção de auto-organização, surgida pela formulação da Segunda Cibernética de Von Foerster, implica que tais capacidades dependem do modo como o próprio cérebro se organiza, a partir das chamadas "redes neurais". A ação ocorre no nível da conexão dos neurônios, que devem ser estudados "como membros de vastos conjuntos que aparecem e desaparecem constantemente durante suas interações cooperativas, onde cada neurônio tem reações múltiplas e diversas consoante o contexto" (Varela, s/d, p. 58).

Essa "virada biológica" das ciências cognitivas é aprofundada por teorias subseqüentes. Dentre os autores "pós-conexionistas" mais conhecidos estão Francisco Varela, Humberto Maturana, Gerald Edelman, que serão abordados por nós, e Antonio Damásio, bem-sucedido divulgador, já mencionado.

Segundo essa vertente pós-conexionista, é a partir de sua própria autoorganização que o indivíduo organiza o mundo à sua volta. Abandona-se, com isso, a idéia de um mundo de objetos físicos preexistente ao qual se tem acesso a partir da correspondência de um código (ou gramática) e de símbolos predefinidos. Ao contrário, o mundo físico, "exterior", é "produzido", por assim dizer, pelo próprio organismo na ação de auto-organizar-se. Esta perspectiva, posterior ao conexionismo, é conhecida como enação, e se volta para a ação ao invés da representação.

A partir da emergência das redes neurais, a percepção, as reações à percepção e o que é percebido se organizam em conjunto. Ao mesmo 
tempo, a ausência de uma gramática ou símbolos predefinidos implica que o desenvolvimento do sistema não segue um encadeamento preestabelecido. As redes que emergem são, de algum modo, contingentes. Dependem das ações do organismo no mundo e do efeito dessas ações no próprio organismo. O determinismo, isto é, a certeza de que, dado um certo input, seguirse-á certo output, presentes no modelo computacional, dão espaço para o imprevisível, a criatividade, o acaso.

Esse organismo, que se auto-organiza, é dono, portanto, não apenas de uma autonomia razoável com relação ao meio, mas também tem um percurso absolutamente individual, próprio, no que tange ao seu desenvolvimento. Isso porque, dada a imprevisibilidade do modelo, cada cérebro vai se organizar de modo absolutamente idiossincrático. Embora seja possível falar de estruturas morfológicas comuns a determinadas espécies, os indivíduos que compõem essas espécies serão biologicamente idiossincráticos ${ }^{7}$.

Hoje em dia, essas duas vertentes convivem, em embates e articulações, nas ciências cognitivas: uma representacional, fundamentada pela contínua analogia com o computador e seus avanços tecnológicos, a conhecida inteligência artificial; e a outra representada pela ascensão da visão biológica, anti-representacional, conhecida como neurociência.

A inteligência artificial permanece referida, de certo modo, ao velho dualismo, já que, na relação entre hardware e software, este pode se desvincular do primeiro, ou seja, um programa pode rodar em outros espaços físicos. Para o neurocientista, porém, não há programa nem prévio, nem fixamente estabelecido, que possa ser desvinculado do corpo que o possui. Não há separação entre corpo e comportamento (entre sistema nervoso + organismo e sua conduta), sendo a história de um estritamente vinculada à história do outro. Isto reforça uma concepção material em que o indivíduo está "encarnado" em seu corpo, não podendo sua existência ser compreendida fora dele.

A paulatina ancoragem das ciências cognitivas na biologia do cérebro afastou-as cada vez mais da interdisciplinaridade que marcou seu surgimento. O paradigma da pesquisa biológica, com sua ênfase nos achados empíricos e na evidência material, passa a ser determinante no desenvolvimento das novas teorias sobre a cognição humana.

Antes de prosseguirmos na caracterização do novo sujeito que surge a partir de tais teorias, apresentaremos de forma breve o percurso dos autores que examinamos.

Humberto Maturana é um biólogo chileno que obteve seu PhD em Harvard, 
no final dos anos 50. Tornou-se inicialmente conhecido por seus estudos sobre a visão e a percepção das cores nos animais, incluindo o homem. Adota, desde então, uma compreensão contrária à influência do exterior na determinação do objeto percebido. No entanto, por ter realizado parte de seus estudos nos Estados Unidos e trabalhado no MIT (Massachusetts Institute of Technology), e apesar de evitar o Laboratório de Inteligência Artificial, recebeu influência das ciências cognitivas. Hoje é professor da Universidade do Chile, divulga seu trabalho e influencia um amplo público, entre filósofos, educadores, terapeutas etc. Maturana construiu seus conceitos ao longo de seu trabalho como pesquisador. Ao abordar a questão do funcionamento do ser vivo, ressaltou a autonomia como a característica do vivente. Daí surgem questões epistemológicas, e elabora uma teoria nomeada Biologia do Conhecer. Deseja, assim, determinar uma concepção científica do estudo do ser humano e de sua cognição.

Francisco Varela, também biólogo, chileno e com $\mathrm{PhD}$ em Harvard, foi aluno de Maturana no Chile, no final dos anos 60, tendo trabalhado com ele no laboratório da universidade. Ao ressaltar a influência que recebeu de seu mestre, Varela acrescenta a descoberta da cibernética e da biologia teórica como importantes na sua formação, além de ter na Fenomenologia um aporte teórico e prático para a compreensão do ser vivo. Varela faleceu recentemente na França (em maio de 2001), onde realizava suas pesquisas desde 1986, no CREA (Centre de Recherche en Epistémologie Appliquée). Parte de sua obra inicial foi escrita com Humberto Maturana, quando formularam conjuntamente o conceito de autopoiese. Parece ter alcançado, porém, uma paulatina independência, criando conceitos que afiguram uma sutil diferença entre os autores. Por exemplo: Maturana não parece ser afeito a comparações entre disciplinas, enquanto Varela, em um dos seus mais importantes livros - The embodied mind - escrito em conjunto com outros autores, propõe construir uma ponte entre a mente e a ciência da mente, articulando um diálogo entre duas tradições: a ciência cognitiva e o budismo. Defende que é a noção de experiência, entendida como predomínio da ação sobre a razão, que construirá esta ponte.

Gerald Edelman, americano, médico e bioquímico, foi prêmio Nobel em medicina, em 1972, por suas pesquisas sobre a estrutura e a natureza química dos anticorpos. Seus trabalhos iniciais, na década de 50, foram voltados para estudos na área de imunologia. Hoje é professor da Universidade de Rockefeller e diretor do Instituto de Neurologia, na Califórnia. Edelman é tipicamente um homem de ciência, tendo praticado a medicina nos anos 50 
e, após este período, desenvolveu pesquisas em vários laboratórios dos Estados Unidos. Propõe, por conseqüência, a formulação de uma teoria da mente baseada na investigação do cérebro e/ou na realidade biológica do sistema nervoso. Em seu livro Bright air and brilliant fire, de 1992, Edelman sintetiza sua teoria biológica da mente, chamando-a de Teoria de Seleção de Grupos Neurais (TSGN) ou Darwinismo Neuronal, por estar baseado na teoria da Seleção Natural de Darwin. Devido a sua formação, Edelman começou a estudar o sistema nervoso comparando-o com o sistema imunológico, caracterizando ambos como sistemas de reconhecimento dos invasores externos ao organismo, procurando classificar as "invasões" como self e não-self. Daí depreende-se uma construção de sujeito, a partir de uma nova compreensão da consciência, que Edelman também tem divulgado a um público mais amplo, levando a possíveis aproximações com a psicanálise, por exemplo (Soussumi, 2000).

É possível afirmar que os três autores expressam o "espírito" de um tempo, por isso os escolhemos para análise. Os três produzem um pensamento que nega qualquer teleologia ou transcendência, um pensamento basicamente anti-essencialista e antimetafísico, que enfatiza a experiência e a ação ${ }^{8}$. Consideram que uma compreensão a respeito do humano deve partir de suas características enquanto ser vivo (dotado de corpo). A partir deste fato, constroem teorias, que tanto se originam no laboratório quanto podem retornar a ele para serem experimentadas

É importante ressaltar que os três autores estão em constante diálogo interno com seus pares, ocupando cargos institucionais, ensinando em universidades e recebendo prêmios oficiais. Dialogam também com um público externo, formado por profissionais interessados em aproveitar suas formulações para práticas especificas, construindo técnicas, no caso da terapia (Maturana, 2000; Varela, 1989), e novas formas de compreensão da patologia, no caso da Psiquiatria (Serpa Jr., 2000). Constroem-se, sobretudo, teorias definidoras de uma nova forma de se conceber o humano, formando um movimento conhecido como "terceira cultura", a partir do qual inúmeros cientistas surgem como um novo tipo de intelectual.

"The third culture consists of those scientists and other thinkers in the empirical world who, through their work and expository writing, are taking the place of the traditional intellectual in rendering visible the deeper meanings of our lives, redefining who and what we are" (Brockman, 1995. Introdução) ${ }^{9}$. 


\section{Auto-organização: Autonomia do Ser Vivo}

Maturana e Varela (1995; 1997), a partir de seus experimentos, afirmam que o mecanismo de funcionamento do sistema nervoso é fechado ${ }^{10}$. Esses autores cunharam o termo clausura operacional, estendido a todo ser vivo, incluindo o ser humano. Este conceito marca uma diferença entre o operar do sistema nervoso e o operar do computador. Pensam, assim, escapar de uma visão representacionista ou solipsista.

Não se vêem como solipsistas porque entendem que o meio participa das transformações do sistema nervoso, perturbando-o e desencadeando mudanças estruturais. Mas enfatizam que, para o operar do sistema nervoso não há dentro nem fora, razão pela qual o meio não determina as mudanças. O que acontece é uma co-deriva, ou seja, o ser vivo e o meio perturbam-se mutuamente, sem que um tenha o outro como causa (acoplamento estrutural). Ambos são sistemas fechados. Descrições que vejam a relação ser vivo/meio como de causa e efeito podem ser feitas por um observador, mas não configuram uma compreensão do operar do ser vivo.

O organismo como um todo e o sistema nervoso de um ser vivo, portanto, são definidos por sua organização e determinados por sua estrutura ${ }^{11}$ - isto é o que caracteriza a autopoiese. Um ser vivo é autopoiético porque gera o seu próprio processo de produção, através da contínua interação de seus componentes, constituindo-se como uma unidade independente no espaço físico.

O sistema nervoso é constituído de uma deriva filogênica (evolução), não obedecendo a qualquer desígnio prévio. Produz um mundo em co-deriva com o meio, especificando as perturbações que, vindas do meio, podem desencadear mudanças no organismo (Maturana e Varela, 1995). Não se trata de adaptação e sim de mudanças que ocorrem naturalmente, sem intenção ou propósito (Teoria da Deriva Natural) ${ }^{12}$, como parte do processo espontâneo do viver.

Buscando escapar de uma visão da representação interna do mundo exterior, Varela cria uma nova perspectiva analítica, conhecida como enação. Afirma, basicamente, que a ação predomina sobre a representação. Deseja, assim, elaborar uma compreensão da cognição que não seja desvinculada do senso comum (nossa história física e social), concluindo pela asserção de um saber "ontológico", ou seja, sujeito e objeto são a especificação um do outro, emergindo na ação. Por conseqüência, o cérebro é um órgão que se baseia na enação de mundos diferentes. É um órgão que constrói mundos, na 
vivência da experiência, e não os reflete (Varela, s/d).

Também para Edelman o sistema nervoso é fechado, não-representacional e capaz de se auto-organizar. Possui uma definição de cérebro como um sistema seletivo de reconhecimento de sinais, crendo obter com isto a vantagem de prescindir de uma idéia de homúnculo no interior do homem. Não há necessidade de uma agência interna centralizadora para explicar a relação entre o sistema nervoso e o exterior. Como não é uma questão de troca de informações, não há uma sucessão sem fim de processadores de informação no cérebro. Não existem homúnculos que interpretem os sinais e os símbolos vindos do exterior. $\mathrm{O}$ modelo do cérebro como um computador, portanto, não explica o processo de cognição.

Edelman (2000a) propõe, então, uma teoria oposta, chamando-a de Teoria da Seleção dos Grupos Neuronais (ou Darwinismo Neuronal) que consiste, basicamente, em compreender o funcionamento do sistema nervoso a partir da relação entre grupos de neurônios. Esses grupos são identificados através de mapas porque operam por pontos de relações com outros grupos. Sinais são percorridos de um lado a outro, entre mapas, ocorrendo diversas conexões paralelas, ao mesmo tempo.

O sistema nervoso, visto como uma "cartografia global", é capaz de ajustar continuamente o comportamento, independentemente dos sinais sensoriais. Ao contrário do que pensamos comumente, a atividade sensóriomotora depende da "cartografia global", que seleciona os grupos neuronais e ajusta o comportamento. A definição de um comportamento adequado é, portanto, um critério exclusivamente interno. Um mecanismo semelhante à seleção natural darwiniana faz com que grupos de neurônios morram, sobrevivam ou sejam fortalecidos. O nível principal em que a seleção natural ocorre encontra-se no indivíduo, devido a suas conexões neuronais, com conseqüências em seu comportamento.

A visão do sistema nervoso como um sistema fechado se alastra a todo o organismo e à relação entre as suas partes. O sistema nervoso, na relação com o organismo, também não é determinado, mas perturbado por ele, tendo como uma das suas tarefas manter o corpo funcionando equilibradamente (temperatura, pressão etc.). Cada parte do organismo, enfim, é vista como fechada e autônoma. 


\section{Sistema Nervoso: uma Diferente Concepção de Consciência e de Sujeito}

Para Edelman (2000a), a consciência humana compõe-se pela integração de dois tipos diferentes de consciência e seu modo de operar. No nível mais básico, está a consciência primária que, encontrada nos mamíferos com sistema nervoso, consiste em uma atividade neuronal, vinculada a certas áreas cerebrais e a percepção sensorial. Essa consciência primária é ativada através das "reentradas" dos sinais entre diversos mapas (grupos de neurônios), associados a distintas modalidades sensoriais. É como estar diante de uma cena (comer uma maçã), experimentando a cada instante uma sucessão contínua de vivências sensoriais (tato, olfato, paladar, visão e audição unem-se na composição da cena). É, assim, uma consciência do presente, vinculada em tempo real às experiências sensoriais. A cada experiência sensorial, porém, há uma atividade neuronal que a precede e a determina como viável ou não. Essa atividade neuronal, chamada por Edelman de "memória de valor", adquire significado por sua evolução ("presente recordado").

A consciência secundária (ou consciência de ordem superior) surgiu com a evolução de certas estruturas cerebrais, que possibilitaram a emergência da linguagem, sendo observada somente nos humanos, embora esteja esboçada em chimpanzés. Essa consciência só é possível se existem a consciência primária e a habilidade de produzir conceitos. É desse modo que funciona: os processos da consciência primária são "recategorizados" mediante padrões de reentrada (sinais trocados entre grupos neuronais) que vão gerando, no longo prazo, modelos relacionados com a noção de self e não- self. Como conseqüência desta modelização, o indivíduo gera modelos de si e do mundo, surgindo uma distinção entre passado, presente e futuro, veiculada pela linguagem e aumentando a flexibilidade do comportamento.

Consciência primária (experiência global e imediata) e consciência de ordem superior ("recategorização", produção de si e do mundo) somam-se para formar a consciência humana. Esta é, portanto, um somatório de sensações, sentimentos que decorrem das experiências sensórias e de modelos conceituais (linguagem). A consciência não é uma instância racional. A razão perde sua importância, passando a ser a conseqüência, e não a causa, de um fenômeno físico, baseado na relação entre o sistema nervoso, o organismo e o meio desencadeante das suas respectivas operações.

Maturana e Varela também esperam compreender a consciência a partir 
do sistema nervoso, entendendo-o como fechado e/ou como autopoiético, ligando razão (pensamento) e emoção (sensação + sentimento) em um mesmo processo físico. Mas, diferentemente de Edelman, não possuem uma teoria que especifique mais diretamente a atividade neuronal e a experiência consciente. A consciência é exclusivamente compreendida como um fenômeno que ocorre na linguagem.

O "espaço psíquico", para Maturana (1997), é compreendido, enfatizando o determinismo estrutural do sistema nervoso, na relação do organismo (conduta) com o meio, isto é, explica o psíquico pelo relacional ${ }^{13}$. A consciência, portanto, é um fenômeno que deve ser entendido pelas descrições feitas na linguagem, de acordo com a conduta consensual de cada indivíduo.

O pensamento de Maturana parece ser causal: o sistema nervoso produz, evolutivamente, seres dotados de linguagem que passam a se descrever fazendo distinções entre si. A consciência de si é explicada pelo surgimento da linguagem humana que, gerando o fenômeno da consciência (no "linguajar"), possibilita ao ser humano o diálogo consigo mesmo, como um outro (autoconsciência). Ambas, a linguagem e a consciência, necessitam do sistema nervoso para ocorrer, mas não estão em seu interior. São fenômenos lingüísticos e sociais (social aqui é entendido como coordenação de condutas). Constituem simplesmente uma capacidade de falar e descrever experiências em conjunto. A consciência é, enfim, uma experiência que se dá na linguagem, no relacional e não a partir de uma entidade interior.

Assim, uma definição de self, que se depreende da neurociência, e vem sendo denominada como "pós-moderna" 14 , caracteriza-se principalmente pela ausência da noção de substância. Não há uma idéia de unidade. Não há a idéia de uma "agência central". Há uma composição da identidade que se dá na linguagem, na descrição de si-mesmo. A consciência é biologicamente determinada, mas não localizável no cérebro, e, por conseqüência, o processo humano de se referir a "si-mesmo" não se dá por uma entidade especial. A figura de uma exterioridade ao self que o definiria, como Deus, deve ser substituída por uma noção de autotranscendência (Dupuy, 1988), isto é, a produção de si-mesmo engendra uma "exterioridade" que lhe é própria, constituindo a identidade pelo fluxo de um self que sempre se reconstrói, um self que é causa de si mesmo ao transformar sua produção.

Outra característica é a comparação com outros animais, levando à conclusão de que nós, humanos, não somos superiores. Somos tão-somente diferentes, pela nossa capacidade de auto-referência, a partir de um relato que se dá na linguagem. Não há um sentido a priori que determine quem 
somos. Há, outrossim, uma evolução em que foi construído o cérebro e o organismo que temos, habilitando-nos para a fala, para a auto-expressão e, assim, inventamos valores morais ou sentidos em nossas relações e conversações.

Os três neurocientistas definem como característica fundamental do ser vivo a sua autonomia, caracterizando o seu modo de operar como independente em relação ao meio. Uma teoria da consciência deve partir desta premissa, fundamentando uma concepção que, intitulada "pós-moderna", reforça categorias modernas, como autonomia, individualidade e liberdade, vestindo-as com novas roupagens biológicas ${ }^{15}$.

\section{Uma Lebensphilosophie Biológica?}

Antes de passarmos ao exame do sujeito da neurociência, cabe uma breve discussão acerca da dualidade que marca a constituição do sujeito moderno e sua relação com a natureza.

Essa dualidade tem sua origem no fato de a pessoa moderna se constituir e ser pensada como um indivíduo - significando que seu pertencimento a uma totalidade, seja ela cósmica ou social, é problematizado. O individualismo moderno assenta-se sobre dois pilares fundamentais: a igualdade e a liberdade. "Todos os indivíduos nascem livres e iguais", reza a Declaração Universal dos Direitos Humanos, que pressupõe uma concepção geral e abstrata - universal - do ser humano, capaz de atravessar séculos, culturas e diversidades biológicas.

Quanto à liberdade, esta pode ser pensada a partir de dois pontos de vista não necessariamente convergentes. De um lado, a liberdade do cidadão, participante de uma sociedade de contrato. De outro, a liberdade de consciência, de crença - como liberdade interior. Esta nos remete à concepção fundamental de interioridade, que, desde pelo menos Agostinho, delineia uma espécie de "espacialidade" (um dentro e um fora) para a pessoa moderna, concebida como dotada de uma vida interior, espiritual que a define intrinsecamente. A interioridade e a liberdade a ela associadas, além de implicarem a afirmação da singularidade desse indivíduo, associaram-se paulatinamente a um plano mental ou psicológico distinto do corporal ou físico.

Em outro trabalho chamamos atenção para a tensão entre essas duas faces do indivíduo moderno: de um lado, a igualdade política e jurídica; de outro, a diferença baseada na completa singularidade interior (Russo, 1995). Referimo-nos aqui à já clássica formulação de Simmel sobre o individualismo 
da singleness (que enfatiza a igualdade) versus o individualismo da uniqueness (baseado na liberdade). Essa dualidade recobre modos diferentes de relação com a natureza. Em As fontes do self, Charles Taylor se refere a duas constelações de idéias formativas do universo de pensamento moderno, vinculando-as a percepções divergentes da natureza:

“(...) uma liga uma percepção intensa de nossas capacidades de razão desprendida a uma leitura instrumental da natureza; a outra concentra-se em nossas capacidades de imaginação criativa e conecta-as a uma percepção da natureza como fonte moral interior. Essas formas apresentam-se como rivais, e a tensão entre elas é um dos traços dominantes da cultura moderna" (Taylor, 1997, p. 532).

Tais percepções estão imbricadas em um conflito constitutivo da pessoa moderna:

\footnotetext{
“Algo fundamental muda no final do século XVIII. O sujeito moderno já não se define apenas pela capacidade de controle racional desprendido, mas também por essa nova capacidade de auto-articulação expressiva - a capacidade que tem sido atribuída desde o período romântico à imaginação criativa. Ela atua, em certos aspectos, na mesma direção que a capacidade anterior: intensifica a sensação de interioridade e leva a um subjetivismo mais radical ainda e a uma internalização das fontes morais. Mas, em outros aspectos, essas capacidades estão em conflito. Seguir a primeira até o fim é adotar uma postura de desprendimento da própria natureza e dos próprios sentimentos, o que torna impossível exercer a segunda. Uma pessoa moderna que reconheça ambas essas capacidades está constitucionalmente em conflito" (Taylor, 1997, p. 499-500).
}

A postura instrumental (personificada no sujeito da razão desprendida), implica a objetificação e neutralização da natureza, vista como separada do sujeito, que por sua vez mantém com relação a ela uma independência moral. A era romântica nos teria legado a aspiração de reunificação: "devolver-nos o contato com a natureza, eliminar as divisões interiores entre razão e sensibilidade, superar as divisões entre as pessoas e criar a comunidade" (Taylor, 1977, p. 492). Segundo Taylor, essa batalha entre, de um lado, a razão instrumental e, de outro, uma concepção expressivista da natureza, continua sendo travada em nossos dias, na controvérsia sobre política ecológica em que duas perspectivas se opõem: 
"[uma que] vê a dignidade do homem em seu controle de um universo objetificado por meio da razão instrumental e outro que afirma a necessidade de se reconhecer que somos parte de uma ordem maior de seres vivos, no sentido de que nossa vida vem dela e é mantida por ela" (Taylor, 1997, p. 492).

Nossa intenção é verificar de que modo a concepção de sujeito que emerge das teorias neurocientíficas se articula a essa dualidade constitutiva do pensamento moderno - a afirmação concomitante de um sujeito "desprendido", capaz de um conhecimento neutro e objetivante, e de um sujeito que é parte de uma totalidade a qual ele só pode conhecer, através da experiência "encarnada".

Uma primeira leitura de nossos autores revela, de imediato, a proposta de uma ancoragem biológica da singularidade e da autonomia. Características que, como vimos mais acima, estão referidas à interioridade propriamente psicológica, aqui passam a se ancorar numa "interioridade biológica" (expressão, como veremos, inadequada).

A ancoragem da liberdade na natureza biológica ou material do homem implica uma radical mudança de perspectiva, já que a afirmação da autonomia do ser humano sempre serviu como argumento contra uma leitura estritamente biológica do homem. Dentro de uma concepção kantiana de um mundo físico "sem alma", essa visão mais tradicional concebia o biológico como sinal de determinismo absoluto e, portanto, falta de liberdade. Do mesmo modo, o estrito determinismo que se atribuía ao mundo material/ natural ia de encontro a uma definição do ser humano como agente criador, original e singular.

A novidade, portanto, da visão fornecida pela neurociência é articular esses valores fundamentais à total naturalização do ser humano ${ }^{16}$. Pois não é apenas nele que a autonomia e a individualidade/singularidade surgem como valores. Ao contrário, só são valores humanos porque são valores do ser vivo em geral, independentemente do seu grau de organização ou complexidade. Os valores humanos por excelência, na verdade, se aplicam a qualquer ser vivo. O homem, sua mente, seu espírito, podem ser naturalizados porque as características básicas de seu funcionamento são as características básicas do funcionamento da natureza como um todo.

Neste sentido, talvez seja possível falar que a naturalização do ser humano é correlata a uma espécie de humanização e, por que não dizer, encantamento da natureza ${ }^{17}$. Esta deixa de ser um objeto (de intervenção, de 
manipulação, de investigação) que se oferece ao espírito humano para se transformar num sujeito de suas próprias transformações. É possível ver nesse movimento a radicalização de uma das características básicas do individualismo moderno: o igualitarismo, isto é, o achatamento das diferenças pela negação de qualquer hierarquia. A naturalização do humano/humanização da natureza nos parece ser claramente a exacerbação da postura antihierárquica e niveladora que caracteriza o universo de valores moderno.

Por outro lado, trata-se do achatamento de um determinado tipo de diferença - uma diferença propriamente hierárquica, porque calcada numa disparidade de valor que implica superioridade de um dos termos sobre o outro (no caso, das capacidades "superiores" do ser humano frente aos outros animais e seres vivos). O achatamento dessa diferença de valor é concomitante à valorização da multiplicidade, da pluralidade e da imprevisibilidade que marcam as diferenças entre indivíduos de uma mesma espécie ou entre espécies. Ou seja, a uma espécie de igualdade radical entre os seres vivos corresponde uma singularidade não menos radical.

A negação de qualquer hierarquia vincula-se a um antiessencialismo extremado. As noções de acaso e contingência, já presentes na teoria darwiniana, são levadas a seu extremo, e a noção de viabilidade é apresentada como justificativa para a existência ou persistência de um determinado ser vivo (ou uma característica deste) ${ }^{18}$. Qualquer idéia de um desígnio, ou de uma predeterminação, é negada. Do mesmo modo, a idéia segundo a qual a sobrevivência depende de uma melhor ou pior adaptação ao meio é descartada, pois suporia uma gradação de valor entre os diferentes organismos ou suas características.

Além disso, a própria noção de auto-organização que, levada ao limite, implica a negação de um mundo prévio ao sujeito, problematiza a noção de adaptação ao meio. Ao contrário, o organismo, ao se auto-engendrar, engendra também o mundo em que vive. A distinção entre dentro e fora se esfumaça, já que a auto-organização pressupõe um acoplamento organismomeio em que cada um dos termos não pode ser pensado separadamente. Esse modo de conceber a relação organismo-meio tem conseqüências importantes no que tange à forma tradicional de se pensar o ser humano.

Em primeiro lugar, a negação de qualquer essência e a ênfase no processo de auto-engendramento implicam a negação do self como algo que existe em si, uma espécie de agência central, responsável pela organização e ordenação das percepções (o que vem de fora) e pelas ações e pensamento (que vêm de dentro). O self, ao contrário, está sempre se constitu- 
indo, é um processo ${ }^{19}$. Essa concepção se assenta na afirmação de uma radical plasticidade das redes neurais que compõem o sistema nervoso.

Esse eu exteriorizado em processo aponta muito mais para o desenrolar de suas ações no futuro do que para nexos causais localizados em sua história passada. Pelo contrário, a própria noção de causalidade se complica dadas a multiplicidade, a complexidade e a imprevisibilidade das conexões neurais. Não se trata tanto de buscar no passado as causas do comportamento presente, mas sim de operar no presente e no futuro, visando a um comportamento mais viável ou mais interessante. Embora a história de cada um seja singular e irrepetível (ou por isso mesmo), ela não produz uma estrutura subjacente passível de análise através dessa própria história (como é o caso com a psicanálise). As conexões e redes que emergem em determinado momento e em determinado contexto, embora possam acionar a memória de conexões e redes passadas, não são "congeláveis" numa estrutura estável, já que novas propriedades globais podem sempre emergir.

A neurociência radicaliza, neste sentido, o "descentramento do eu" já esboçado pela psicanálise. De fato, todo o arcabouço teórico da psicanálise se construiu em torno do tema da divisão de si, isto é, da negação de uma unidade ou coerência do eu. Entretanto permanece, de algum modo, a idéia de uma espécie de "agência central", o ego, mesmo que sua ação como "agência central" seja uma ilusão frente às exigências do id e do super-ego. A diferença crucial parece-nos estar na permanência de uma hierarquia ou um certo tipo de organização (ou estrutura) entre as diferentes instâncias que compõem o sujeito, o que não é o caso agora, na neurociência. A multiplicidade subjacente ao self (que dá a idéia de múltiplos selves) não implica qualquer hierarquia. E, longe de ser o sinal de algum tipo de sofrimento ou destino trágico do ser humano, como é o caso da relação conflituosa ego-id-superego, constitui-se numa característica positiva e desejável, pois aponta para a plasticidade, a capacidade adaptativa e criativa do ser vivo em geral (e do ser humano em particular).

A afirmação de uma radical plasticidade do sistema nervoso e do seu funcionamento de fato distancia a neurociência do decantado pessimismo freudiano. Por um lado, a indeterminação/imprevisibilidade dos seres vivos, bem como sua originalidade e capacidade de responder criativamente a situações também imprevistas são enfatizadas. Por outro, as possibilidades de auto-aperfeiçoamento, auto-reparação, expansão das próprias possibilidades aumentam exponencialmente. De fato, toda uma "puericultura neurocientífica", por exemplo, tem surgido com o objetivo de ensinar pais, 
professores e cuidadores de um modo geral, a desenvolver apropriadamente as capacidades cognitivas/intelectuais das crianças desde a mais tenra idade. A neurociência nada mais faz que seguir e aprofundar o caminho já traçado pela chamada medicina do comportamento (psiquiatria, psicanálise, psicologias), oferecendo um aconselhamento especializado na arte do "bem-viver". Há, entretanto, uma diferença importante. O trabalho sobre si, proposto por esse novo aconselhamento científico, não envolve um processo reflexivo de auto-exame. Trata-se, ao contrário, de uma espécie de "autocultivo" exteriorizado, que se processa no fazer, na experiência de viver, não em uma indagação sobre si. Como já vimos, é a própria idéia de uma interioridade propriamente espiritual ou psicológica que é descartada.

Voltamos à afirmação feita mais acima: o radical desencantamento ou dessacralização das qualidades distintivas do ser humano parece corresponder a um "re-encantamento" da natureza. Se o ser humano pode ser "reduzido" à sua natureza de ser vivo, se toda sua complexidade (pensamento, razão, consciência, linguagem) pode ser compreendida a partir dessa natureza, é porque a natureza em si possui as qualidades que antes atribuíamos apenas ao ser humano. A natureza é capaz de intencionalidade, autonomia e criatividade. Neste sentido, pode-se falar numa totalidade "físico-moral", não apenas no que diz respeito ao sujeito humano - no qual a separação corpo/ mente deixa de fazer sentido - mas também, e principalmente, no que tange ao mundo dos seres vivos como um todo. A "moral" ou o valor estão entranhados (encarnados) no próprio modo como a vida se organiza no planeta. Neste sentido, acreditamos ser possível falar de um mundo físico "re-encantado". O que nos leva de volta a uma questão colocada nas nossas observações preliminares: a articulação possível entre a visão de mundo proposta pela neurociência e o movimento contracultural da segunda metade do século XX.

Como vimos, a atual tendência à adoção de uma visão totalmente naturalizada do ser humano - sobretudo daquelas características, tais como consciência, razão, linguagem, que tradicionalmente o distinguiam dos outros animais - corresponde à ancoragem do espírito no corpo, o que significou, não tanto uma redução materialista do humano, mas uma transfiguração espiritual da natureza material. Esta, como se viu, passa a ser dotada de características tradicionalmente vistas como humanas, numa espécie de neovitalismo sem princípio vital. Parecemos estar frente a uma Lebensphilosophie materialista ${ }^{20}$, fundada em uma crítica ao paradigma racionalista clássico e ao materialismo mecanicista e afirmando a vida como 
valor supremo.

À guisa de conclusão, é possível afirmar que o "sujeito da neurociência", tal como se depreende da leitura dos trabalhos de Varela, Maturana e Edelman e seus comentadores, não parece tanto se fundamentar na negação dos pressupostos que sustentam o sujeito moderno, mas sim na sua radicalização. Como vimos, singularidade/originalidade e autonomia são características fundantes daquele. Do mesmo modo, a negação anti-essencialista do "self" pode ser interpretada como a radicalização do "descentramento do sujeito" proposto pela psicanálise e presente em importante vertentes do pensamento filosófico do século $\mathrm{XX}$, calcadas na crítica à visão unitária e coerente do eu.

A leitura radicalmente materialista do espírito, numa espécie de "nova aliança" entre homem e natureza, por sua vez, nos remete à velha aspiração de "reunificação romântica" a que se referiu Taylor.

Por outro lado, é verdade que o sucesso da leitura "neurocientífica" do ser humano faz parte da "virada biológica" mais ampla a que nos referimos em nossa introdução. Essa virada, sabemos, é motivo de grande preocupação, já que o sonho totalizante da biologia como uma ciência unificadora, aliado ao desenvolvimento aparentemente ilimitado da biotecnologia, guarda semelhanças assustadoras com o pesadelo eugênico dos anos 30. No entanto, embora fazendo parte do "ufanismo biológico" que alimenta a biotecnologia, a leitura hipernaturalista do humano empreendida pela neurociência, como vimos, leva a uma espécie de "re-encantamento" da natureza, aproximandose das críticas ecológicas ao cientificismo mecanicista e instrumental.

Neste sentido, a atual hegemonia do paradigma biológico contempla as duas vertentes que, citando Charles Taylor, assinalamos como constitutivas do "universo do pensamento moderno" - a razão desprendida e a natureza como fonte moral. Seu contínuo enfrentamento parece ser a garantia de que nossa aproximação de um admirável mundo novo huxleyano é uma ameaça às vezes perigosamente palpável, mas nunca realizada. 
Jane A. Russo e Edna L. T. Ponciano

\section{Referências Bibliográficas}

BEZERRA JR., B. Naturalismo como anti-reducionismo: notas sobre cérebro, mente e subjetividade. Cadernos IPUB, Rio de Janeiro, v. 6, n. 18, p.158-177, 2000.

BROCKMAN, J. The third culture: beyond the scientific revolution. New York: Simon \& Schuster, 1995.

CAMPBELL, C. The romantic ethic and the spirit of modern consumerism. Oxford: Blackwell, 1987.

A orientalização do Ocidente. Religião e Sociedade, Rio de

Janeiro, v. 18, n. 1, p.5-22, agosto, 1997.

CASTEL, R. Gestão dos riscos. Rio de Janeiro: Francisco Alves, 1987.

COSTA, J. F. Ordem médica e norma familiar. Rio de Janeiro: Graal, 1979.

DAMASIO, A. O erro de Descartes. São Paulo: Companhia das Letras, 1996.

DENNETT, D. The self as a center of narrative gravity. In: KESSEL ; JOHNSON. Self and consciousness: multiple perspectives. Philosophia, New Jersey, v. 15, p.275-288, 1986.

Autumn, 1989.

The origins of selves. Cogito, New Jersey, v. 3, p.163-173,

. Tipos de mentes: rumo a uma compreensão da consciência. Rio

de Janeiro: Rocco, 1997.

DONZELOT, J. A polícia das famílias. Rio de Janeiro: Graal, 1980.

DUARTE, L. F. Formação e ensino na antropologia social: os dilemas da universalização romântica. In: OLIVEIRA, J. P. O ensino da antropologia no Brasil. Temas para uma discussão. Rio de Janeiro: Associação Brasileira de Antropologia, 1995. p. 131-146.

DUPUY, J. P. L'homme machine et les adorateurs du signifiant: Cybernétique et sciences de l'homme. Le Débat, Paris, v. 49, mars/avril, p. 32-49,1988. . Aux origines des sciences cognitives. Paris: Éditions La Découverte, 1994.

EDELMAN, G. M. Biologie de la conscience. Paris: Éditions Odile Jacob, 2000a.

Gerald M. Edelman, théoricien de la conscience. La Recherche, Paris, p.109-111, sept., 2000b.

FAVERET, B. Trieb X Instinkt: uma distinção a ser refinada. Psicologia Clínica - Pós-Graduação e Pesquisa, Rio de Janeiro, v. 8, 1996/7. 
FOUCAULT, M. História da sexualidade I: a vontade de saber. Rio de Janeiro: Graal, 1988.

GERGEN, K. J. El yo saturado. Madrid: Editorial Paidós, 1992.

GRACIANO, M. M. C. A teoria biológica de Humberto Maturana e sua repercussão filosófica. Dissertação (Mestrado) - Faculdade de Filosofia e Ciências Humanas, Universidade Federal de Minas Gerais, 1997.

LAND, M. A mente externa: a ética naturalista de Daniel Dennett. Rio de Janeiro: Garamond, 2001.

MATURANA, H.; VARELA, F. A árvore do conhecimento. Campinas: Editorial Psy, 1995.

De máquinas e seres vivos: autopoiese - a organização do vivo. Porto Alegre: Artes Médicas, 1997.

MATURANA, H. A ontologia da realidade. Belo Horizonte:UFMG, 1997. Seres humanos individuais e fenômenos sociais humanos. In:

ELKAÏM, M. (Org.). Terapia familiar em transformação. São Paulo: Summus, 2000. p.144-149.

MORIN, E. A noção de sujeito. In: SCHNITMAN, D. F.(Org.). Novos paradigmas, cultura e subjetividade. Porto Alegre: Artes Médicas, 1996a. p.45-58.

. Ciência com consciência. Rio de Janeiro: Bertrand Brasil, $1996 \mathrm{~b}$. PRIGOGINE, I.; STENGERS, I. La nouvelle alliance. Paris: Gallimard, 1986.

RUSSO, J. A. Indivíduo e transcendência: algumas reflexões sobre as modernas religiões do eu. Doxa - Revista Paulista de Psicologia e Educação, Araraquara, v. 3, n. 1 e 2, p.9-33, 1997.

SEARLE, J. O mistério da consciência. São Paulo: Paz e Terra, 1998. SERPA JR., O. D. Mente, cérebro e perturbação mental: a natureza da loucura ou a loucura na natureza? Cadernos IPUB, Rio de Janeiro, v. VI, n. 18, p.144-157, 2000.

SOUSSUMI, Y. Perspectivas para uma neuro-psicanálise. Psicanalítica. $S P R J$, Rio de Janeiro, v. 11, n. 1, p.78-101, 2000.

TAYLOR, C. As fontes do self. São Paulo: Edições Loyola, 1997.

VARELA, F.; THOMPSON, E.; ROSCH, E. The embodied mind. Cambridge, The MIT Press, 1996.

VARELA, F. Conhecer: as ciências cognitivas, tendências e impasses. Lisboa: Instituto Piaget, [19-], 100p.

. Reflections on the circulation of concepts between a Biology of Cognition and Systemic Family Therapy. Family Process, v. 28, n. 1, p.15- 
24, March, 1989.

A individualidade: a autonomia do ser vivo. In: VEYNE, P. et al. (Org.). Individuo e poder. Lisboa: Edições 70, 2000. p.105-112.

\section{NOTAS}

1 Antropóloga, professora adjunta do Departamento de Políticas e Instituições de Saúde, Instituto de Medicina Social da UERJ.

2 Psicóloga, doutoranda do Programa de Pós-graduação em Psicologia Clínica da PUC-RJ.

3 Colin Campbell, em seu texto "A orientalização do Ocidente", afirma que a teodicéia cristã, tradicionalmente hegemônica na cultura ocidental, estaria sendo substituída por outra, que ele chama "oriental", não por influência de uma pretensa "cultura oriental", mas pela ascensão de uma vertente até então dominada da própria cultura ocidental, vertente esta que ele identifica ao movimento romântico e seus sucedâneos. Outros autores, como Charles Taylor e, entre nós, Luiz Fernando Duarte, argumentam a favor de uma tensão constitutiva entre essa vertente romântica e o racionalismo universalizante que a ela se opõe (Taylor, 1997 e Duarte, 1994).

4 Não vamos discutir aqui a questão certamente importante da difusão diferencial da psicanálise (e de qualquer outro conhecimento "douto") entre indivíduos pertencentes a camadas sociais diversas e com diferentes níveis de escolaridade.

5 Em The romantic ethic and the spirit of modern consumerism, Collin Campbell chama atenção para o claro parentesco entre o movimento contracultural do século XX e o movimento romântico que marca a passagem do século XVIII para o XIX.

6 Estamos deixando de fora toda a importantíssima discussão sobre a relação corpo-mente levada a cabo no interior da filosofia da mente contemporânea, cujo diálogo com a neurociência é intenso. Também ao escolher esses autores, deixamos de lado outra vertente (como a representada por Francis Crick ou Roger Penrose), cujo reducionismo fisicalista é mais marcado, dificultando o intercâmbio com as ciências humanas (Searle, 1998). As teorias de Varela, Maturana e Edelman, ao contrário, freqüentam com desenvoltura o discurso de psicólogos, psicanalistas, filósofos e mesmo sociólogos up to date, o que certamente as qualifica como sérias candidatas a Weltanschauungen contemporâneas.

7 Após descrever a complexidade envolvida no funcionamento cerebral, Edelman afirma: "Il est presque impossible d'établir des comparaisons entre individus concernant le nombre de combinaisons moléculaires significatives qui interviennent dans une telle séquence d'évenements, même lorsqu'il s'agit de jumeaux identiques" (Edelman, 2000a, p. 257-8)

8 Podemos encontrar uma fonte de inspiração para esses autores na história da filosofia americana que, segundo Land (2001), tem como principal corrente o naturalismo pragmático, tendo sofrido a influência do materialismo, do empirismo e do positivismo lógico.

9 Mais informações e o texto completo do livro citado podem ser encontradas na página 
www.edge.org. Lá se encontram textos e posicionamentos desses novos intelectuais, inclusive os mencionados por nós. Argumentamos no decorrer deste artigo que essa redefinição proposta pela "terceira cultura", bem como a concomitante ênfase na experiência e na ação, localiza-se no interior da voga neo-romântica contemporânea, a que Campbell se refere como "orientalização do Ocidente" (ver nota 4).

10 Um exemplo é continuamente retomado em suas argumentações. Trata-se de um experimento realizado com um girino. Foi cortada a borda do seu olho, sem tocar no nervo óptico, girando o olho até completar 180 graus. O animal desenvolveu-se até a fase adulta. Foi mostrado um verme ao sapo de laboratório, cobrindo o olho que foi virado. Ele acerta o alvo com sua língua. O experimento foi repetido cobrindo o olho normal e o sapo projeta a língua com um desvio de 180 graus, errando o alvo. Maturana e Varela chegam à conclusão de que o "sapo projeta a língua como se a zona da retina onde a imagem da presa se forma estivesse em sua posição normal". Por conseqüência, é demonstrado, pela conduta deste animal, que o espaço do mundo exterior não existe, já que não recebe uma informação espacial e sim uma orientação advinda de "uma correlação interna entre o lugar de onde a retina recebe uma determinada perturbação e as contrações musculares que movem a língua, a boca, o pescoço e, em última instância, todo o corpo do sapo" (Maturana e Varela, 1995, p. 157).

11 "Chamarei a esses elos necessários entre elementos constitutivos que dão a um sistema a identidade invariável, a sua organização. E chamarei a tudo que muda, embora permanecendo sujeito à organização, a estrutura do sistema" (Varela, 2000, p. 106).

12 Influenciado por Darwin, pelo aspecto da evolução (transformação contínua), Maturana tece, entretanto, algumas críticas, construindo uma teoria da evolução diferenciada (Graciano, 1998). Sua teoria é isenta de uma conotação competitiva, encontrada inicialmente em Darwin, quanto à sobrevivência das espécies; e também isenta de uma determinação genética estrita (pós-Darwin), em que o meio não desempenharia nenhum papel. A evolução, para Maturana, é um somatório de processos, determinados estruturalmente, que ocorrem no interior do ser vivo, mais sua conduta no meio em que vive.

13 Graciano, em sua tese sobre Maturana, explica: "Maturana funde os termos 'psíquico', 'mental' e 'espiritual', e aponta o domínio de nossa conduta como o domínio de existência desses fenômenos" (Graciano, 1997, p. 29).

14 Dennett, filósofo da mente, articulador da inteligência artificial e das descobertas da biologia, defende uma idéia de múltiplos selves, análoga à experiência que costuma receber o diagnóstico psiquiátrico de personalidade múltipla (Dennett, 1986; 1989; 1997). Gergen (1992), psicólogo social, também é defensor de uma noção de self composto por múltiplas identidades, característico da "pós-modernidade", mas não faz referências à biologia. O universo desta compreensão de self vem, portanto, se estendendo.

15 Os autores tematizados descartam cientificamente a visão de um sujeito com uma substância intrínseca e mundo interno independentes do corpo, tal como propunha Descartes no início da modernidade. Conjugam o operar do ser vivo autônomo (mas sem alma) com a produção de uma dinâmica sempre original, nunca transcendendo o corpo. Dessa forma, nós, seres humanos, tornamo-nos, mais e mais eficientemente, observadores e construtores da nossa própria realidade individual e social. O mundo só existe para cada indivíduo singular a partir dos sentidos construídos a posteriori na linguagem. Há muitos selves que podem ser descritos. Cada self vai assim emergindo na relação entre seres que se autocriam e configuram o seu meio. Neste sentido, o social é sempre uma construção que parte de uma iniciativa individual, sendo caracterizado pela singularidade de cada parte envolvida e não por um todo que predominaria sobre as partes (Maturana e Varela, 1997; Edelman, 2000a; Maturana, 2000). 
16 Da cibernética ao conexionismo, observa-se a passagem de máquinas com uma finalidade préprogramada (reducionismo) para "máquinas" autônomas (complexidade). A autonomia, anteriormente vista como originada de uma fonte espiritual, agora é material. Essa nova visão de autonomia, mesmo sendo vista como fruto de um modo de operar maquinal que caracteriza todo ser vivo, reforça a produção da diferença exponencialmente, caracterizando a vida por esta autoprodução (Dupuy, 1988).

17 Já em 1979, data da primeira edição de seu livro La nouvelle alliance, Illya Prigogine e Isabelle Stengers - ele detentor de um prêmio Nobel em química, ela química e filósofa da ciência - referiam-se a um re-encantamento do mundo a partir do novo paradigma surgido nas ciências a partir de meados do século XX.

18 Segundo Faveret, "o mundo vivo também é um mundo totalmente marcado pela indeterminação, em que os 'possíveis', as 'contingências' e as 'circunstâncias' são os únicos eixos a orientar a atividade vital. Se há alguma determinação que se imponha sobre o ser vivo, é apenas a de que ele se mantenha viável, num processo incessante" (Faveret, 1996/7, p. 68).

19 "Desta forma, os seres vivos têm uma identidade flutuante, que se afirma em e por seu funcionamento, uma identidade processual" (Faveret, 1996/7, p. 66).

20 A Lebensphilosophie surge na Alemanha na virada do século XIX para o século XX, tendo como seus expoentes Dilthey, Simmel, Scheler, Jaspers e Henry Bergson, na França. É um movimento de revitalização sustentado na crítica ao materialismo mecanicista, ao individualismo extremado e ao racionalismo cientificista. Retoma de Nietzche a afirmação de uma Nova Ordem, de uma sociedade revitalizada. Toma a vida como valor supremo, enfatizando a experiência e a intuição em detrimento do empirismo e da razão. 


\section{ABSTRACT}

The Subject in Neuroscience: from the Naturalization of Man to the Re-Enchantment of Nature

The objective of this article is to circumscribe the concept of subject that emerges from neuroscientific theories of the mind. We approach three key authors from the field of neuroscience: Francisco Varela, Humberto Maturana, and Gerald Edelman. Based on an analysis of their work, we conclude that a given concept of subject, founded on an entirely materialist view of the mind, emerges as an advantageous substitute for what we could call a "psychological" concept, based principally but not exclusively on psychoanalysis. We discuss the hypothesis that the current success of the "neuroscientific" vision of human beings, while in fact pointing to some degree of break with the so-called "modern paradigm", may also be interpreted as the radicalization of given characteristics and contradictions present in the constitution of this paradigm itself and, consequently, that of the modern person.

Keywords: Neuroscience; modern person; mind.

Recebido em: 01/11/2002.

Aprovado em: 02/12/2002. 